\title{
Transient Blindness due to Posterior Reversible Encephalopathy Syndrome (PRES) in a Patient of Beta-thalassemia Major
}

\section{Muhtamim Chowdhury ${ }^{1}$, Purushuttom Baniya ${ }^{1}$, Vijay Kumar Raut ${ }^{1}$, Fahtiha Nasreen ${ }^{2}$, Tonazzina Hossain Sauda ${ }^{3}$, Zakia Jabin Loskor ${ }^{4}$, Md Moshiur Rahman ${ }^{5 *}$ and Asifur Rahman ${ }^{1}$}

${ }^{1}$ Department of Neurosurgery, Bangabandhu Sheikh Mujib Medical University, Bangladesh

${ }^{2}$ Department of Orthopedic Surgery and Traumatology, Armed Forces Medical College, Bangladesh

${ }^{3}$ Department of Internal Medicine, Bangladesh Medical College, Bangladesh

${ }^{4}$ Department of Gynaecology and Obstetrics, Central Hospital, Bangladesh

${ }^{5}$ Department of Neurosurgery, Holy Family Red Crescent Medical College Hospital, Bangladesh

*Corresponding Author: Md Moshiur Rahman, Department of Neurosurgery,

Holy Family Red Crescent Medical College Hospital, Dhaka, Bangladesh.
Received: August 14, 2020

Published: September 07, 2020

(C) All rights are reserved by Md Moshiur

Rahman., et al.

\begin{abstract}
Posterior Reversible Encephalopathy Syndrome (PRES) is a clinical but mostly radiological diagnosis with a wide variety of etiologies that is commonly underdiagnosed and missed due to the complete reversibility of its course. The pathophysiology lies in the raised blood pressure that disrupts the internal autoregulation within brain. Ours is a patient who presented as such, is a diagnosed case of B-thalassemia major. One previous author reported of PRES in gravid women with abnormal blood picture which being a rarity interested us in reporting this case [1]. Diagnosis now is more MR based but treatment yet remains elusive and mostly symptomatic.

Keywords: Posterior Reversible Encephalopathy Syndrome (PRES); Headache; Thalassemia; Transient Blindness
\end{abstract}

\section{Introduction}

Posterior Reversible Encephalopathy Syndrome (PRES) is a clinico-radiological diagnosis, previously unrecognized or overlooked due to other major ailments of the patient. The condition has been in consideration since the use of MR imaging in the modern era of radiology. This name is synonymous with Reversible Posterior Leuco-encephalopathy Syndrome (RPLS) [2]. The hallmarks of this condition are headache, confusion, seizures, focal neurological deficits, cortical visual disturbances and blindness [3]. All these are reversible and transient with complete recovery occurring in patients within 48 hours to 2 weeks. The factors bringing in the condition is highly variable ranging from obstetrical, medical, and drug toxicities to autoimmune disease. Pathophysiological explanation is invariably due to disruption of autonomic vasomotor control secondary to severely raised blood pressure [3]. The anatomical predilection is mostly in the regions of the brain supplied by the posterior circulation, radiologically and microscopically affecting the subcortical white matter.

\section{Case Report}

A 34 years old female presented with severe pain in the abdomen for 3 days associated with nausea and multiple episodes of vomiting. She is a diagnosed case of Beta-thalassemia major, and has received multiple episodes of blood transfusion. She was on oral iron and vitamin supplements and was receiving desferrioxamine injections to prevent iron overload. Her lab works revealed a severely low hemoglobin of $4.4 \mathrm{mg} / \mathrm{dl}$, Total count of RBC of 2.5 X 10 12 L, MCV- 68 fL, MCH- 17 pg, MCHC- 25 g/dl, AST- 119 U/L, Alkaline phosphatase- 112 U/L, ALT- 149 U/L, Serum Ferritin$6,320 \mathrm{ng} / \mathrm{ml}$. Cardiac evaluation revealed good LV systolic function of $60 \%$, with no regional wall motion abnormality but presence of moderate pulmonary hypertension. On evaluation for her sudden 
abdominal pain, USG of whole abdomen was done which revealed cholelithiasis with biliary sludge, with hepato-splenomegaly and mild right sided pleural effusion. After her admission she received 3 units of whole blood transfusion on alternate days. But on the $8^{\text {th }}$ day of her stay she suddenly developed severe headache with loss of vision. On examination blood pressure was raised to 165/100 $\mathrm{mmHg}$ and pulse was 52 beats/min and her breathing pattern was labored. She was showing signs of raised ICP. On neurological examination the patient was found to be in a confused state and pupillary reaction was normal and there was no blinking in response to stimulus suggesting of a bilateral cortical blindness. On fundoscopic examination no retinal or disc change was found.

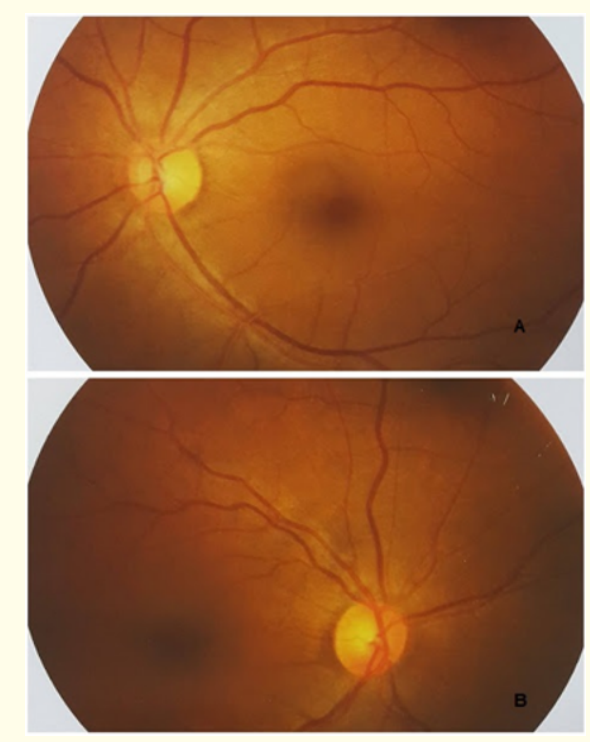

Figure 1: A - Left eye B - Right eye.

MR imaging on both T1 and T2 and FLAIR reveals bilateral cortical hyper-intensities in the posterior part of both occipital, parietal and temporal regions. There is also mild restriction of diffusion in DWI. ADC images were not acquired which might have given a better understanding to the type of edema in progression.

The patient was treated with $20 \%$ mannitol and IV steroids. This resulted in complete resolution of her symptoms within 48 hours and the rest of her stay was uneventful. We couldn't document radiological improvement as the patient was reluctant to do a new image due to financial constraints. On follow up the patient had no further issues with vision and still continued to refuse to do a follow-up MRI.

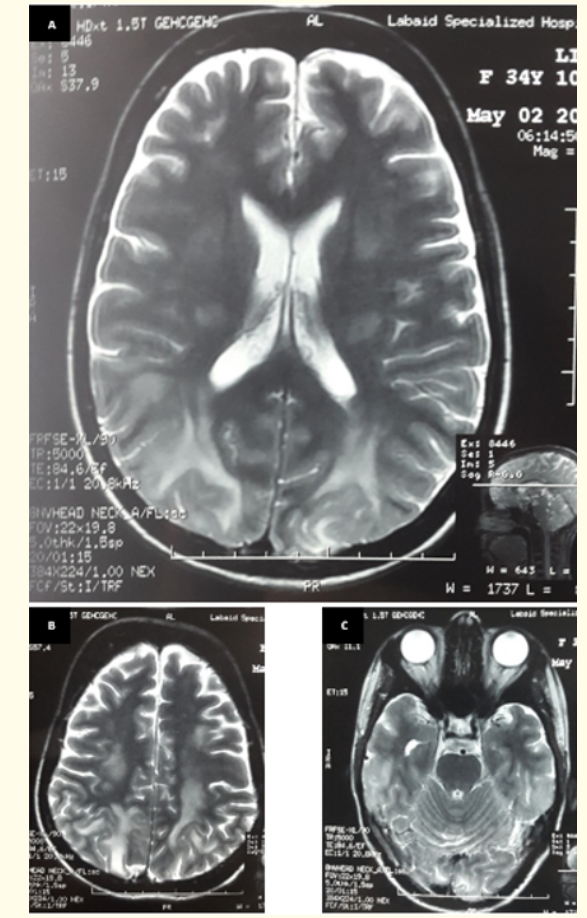

Figure 2: T2 Axial showing A - Occipital, B - Parietal and $\mathrm{C}$ - Temporal hyperintensities.
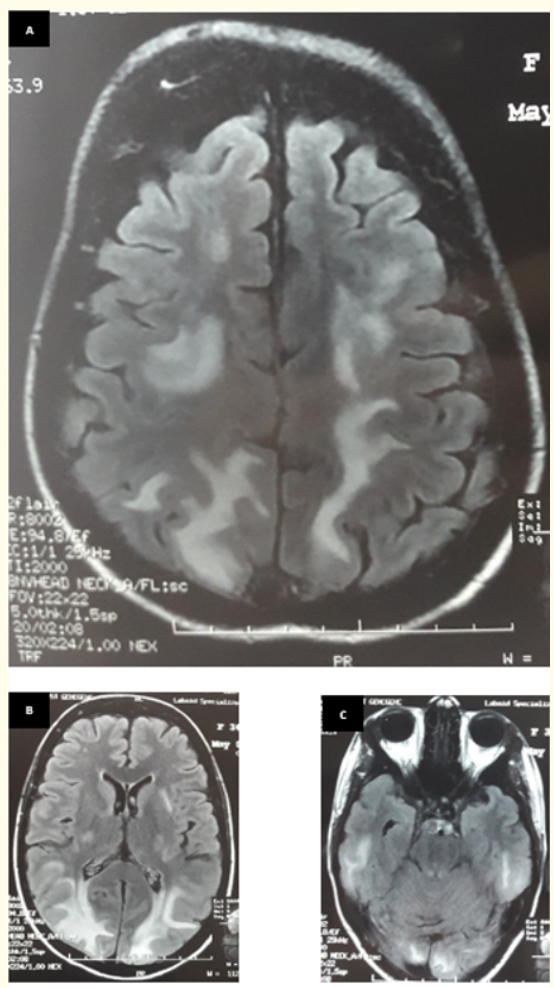

Figure 3: T1 Axial images showing hyperintensities in A - Parietal, B - Occipital, and C - Temporal lobes. 


\section{Discussion}

Posterior Reversible Encephalopathy Sydrome was first described by Hinchey et al in 1996 as combination of neurological and radiological stigmata $[4,5]$. The advent of the modern era of MR imaging has facilitated previously undiagnosed cases to be detected and prevented.

\section{Pathophysiology}

The pathophysiological hypotheses to explain the aetiology of PRES is based on the model describing the disruption of normal auto-regulatory mechanisms of the brain, due to a sudden increase in blood pressure. Following loss of normal physiology of the blood-brain barrier, results in vaso-genic edema $[2,6,7]$. The predilection for this condition, effecting posterior parts of the brain is explained by the sparse sympathetic innervations of the vertebrabasilar system $[3,8,9]$. Microscopically, white matter is more effected compared to that of the tightly packed cortex.

\section{Aetiology}

The causative factors of PRES are highly debatable. Most authors point to the persistently raised BP in most of their patients. But cases had been reported which suggests that patients with minimal elevation or normal blood pressure may present with PRES [7]. Drugs such as cyclosporine, tacrolimus, and other immuno-suppressive agents has been attributed to the cause of PRES $[4,10]$. These agents increase vessel permeability and cause percolation of fluid into the white matter tracts. In a group of women with eclampsia/preeclampsia, PRES was found to be associated with abnormal red cell values rather than their hypertensive levels $[1,11]$. In our case even though the patient is not gravid but presents with beta-thalassemia major with history of multiple blood transfusions and splenomegaly. Her blood picture was highly dysmorphic and it can be speculated that our patient had a similar preconditioning effect on the vascular and probably the hematological territories facilitating recurrent vasogenic edema. Predictability of PRES is a long shot but one author did find a significant association between risk factors including hypertension, renal failure and particularly chemotherapy [12].

\section{Clinical features}

Headache, altered mentation ranging from drowsiness to stupor, confusion, seizures, vomiting and abnormalities of visual perception are well documented. The onset is usually subacute but may be acute, and may be heralded by a seizure, although our patient did not present as such. Of those who presented as such, had multiple and generalized seizures, one author was of the opinion of epileptic syndrome in these patients [13]. Patients are often reported to have blurred vision, hemianopia, visual neglect, and frank cortical blindness may occur. Our patient completely had no vision at all. Deep tendon reflexes are often brisk, and some patients have weakness and incoordination of the limbs [1-3,14].
Diagnosis

Radiology is the corner stone in diagnosing PRES. Previously the entity of PRES was overlooked and was mostly underdiagnosed. Clinical and radiological correlation has given a better understanding into the syndrome. MR sequences of T2, FLAIR, Diffusion-weighted and Apparent diffusion coefficient imaging is used in localization and pin-pointing the type of edema occurring; establishing PRES as more caused by vasogenic rather than cytotoxic edema [7]. The most observed is bilateral symmetrical subcortical hyper-intensities in $\mathrm{T} 2$ and FLAIR sequences effecting the subcortical white matter in the posterior regions of the brain [15]. On Computed Tomography scanning the lesion appears hypo-dense with pattern similar to that of infarction. But the confusion is cleared on DWI and ADC sequences. In DWI increase or decrease in diffusion correlates to cytotoxic and vaso-genic edema respectively. ADC map can be elaborated from DWI and provide a quantitative measurement of the diffusion of water molecules. ADC map shows a decreased signal in case of cytotoxic edema, whereas high ADC values are consistent with highly mobile water in areas of vasogenic edema $[15,16]$.

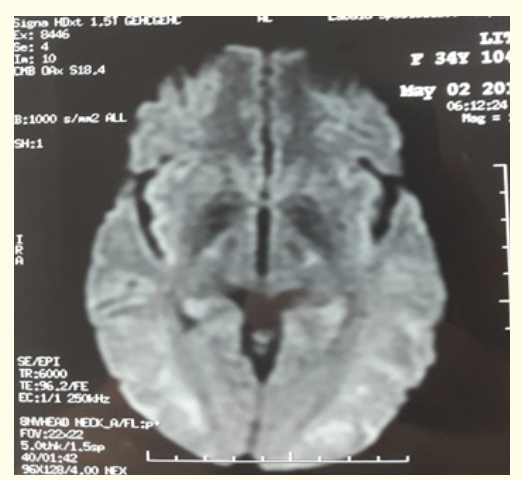

Figure 4: DWI showing restricted diffusion in our patient.

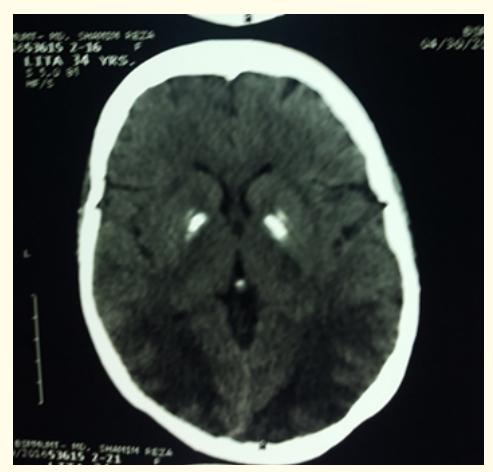

Figure 5: CT scanning of brain resembling ischemic infarct in our patient. 
Treatment

Effective treatment modules are highly variable with multiple authors primarily depending on symptom directed treatment, mostly targeting to normalize the high blood pressure, of which calcium channel blockers (nicardipine or nimodipine is of choice, due to its inherent anti-spasmodic action on cerebral vessels) or beta-blockers as the first-liners. Sodium nitroprusside or hydralazine can be used secondarily [17]. Anti-convulsants are also commonly used, but our patient had not experienced any seizure and did not require as such. We used dexamethasome $(5 \mathrm{mg} / \mathrm{kg} /$ day $)$ and $20 \%$ mannitol (2g/kg over 30-60mins, 8 hourly). Our goal was to reduce the vascular seepage and prevent further cerebral edema. Due to the volume depleting effect of mannitol itself we held on to our decision of avoiding the use of antihypertensives. Complete reversal of symptoms in our patient occurred within 36 hours and improvement of vision started after 12 hours of initiation of the treatment. Authors suggested a reversal or regression period ranging from days to several months if including radiology [18-20].

\section{Conclusion}

The sad part of this report is that of failure to motivate the patient to repeat a follow-up MRI scan. But from the complete restoration of vision we can safely arrive to the conclusion of reversal of the condition. This condition is highly diagnosable, but is easily missed due to commonly being cited as infarction. But entities can be easily differentiated with proper MR imaging and clinical correlation. Thus, one feels reluctant to diagnosed this case to be cited as 'Hypertensive Encephalopathy' as the patient shows no signs of long-standing sequelae. In our opinion this highly undiagnosed syndrome should be familiar to all to prevent long standing complications. One is of the opinion that causative factors of PRES other than hypertension should be sought in case of patients with abnormal blood picture.

\section{Limitations}

Follow-up MRI was not possible due to financial constraints of our patient.

\section{Conflict of Interest}

There is no conflict of interest in the composition of this paper.

\section{Bibliography}

1. Schwartz RB., et al. "Preeclampsia-eclampsia: clinical and neuroradiographic correlates and insights into the pathogenesis of hypertensive encephalopathy". Radiology 217.2 (2000): 371-376.

2. Hinchey J., et al. "A Reversible Posterior Leukoencephalopathy Syndrome". The New England Journal of Medicine 334.8 (1996): 494-500.
3. Hagemann G., et al. "Recurrent posterior reversible encephalopathy syndrome (PRES)". Journal of Human Hypertension 18.4 (2004): 287-289.

4. Moawad FJ., et al. "Transient blindness due to posterior reversible encephalopathy syndrome following ephedra overdose". Southern Medical Journal 99.5 (2006): 511-514.

5. Stevens T., et al. "Two patients with acute liver injury associated with use of the herbal weight-loss supplement hydroxycut". Vol. 142, Annals of internal medicine. United States (2005): 477-478.

6. Khan SJ., et al. "Posterior Reversible Encephalopathy Syndrome in Pediatric Cancer: Clinical and Radiologic Findings". Journal of Global Oncology 4 (2018): 1-8.

7. Ay H., et al. "Posterior leukoencephalopathy without severe hypertension: utility of diffusion-weighted MRI". Neurology 51.5 (1998): 1369-1376.

8. Edvinsson L., et al. "Autonomic nerves, mast cells, and amine receptors in human brain vessels. A histochemical and pharmacological study". Brain Research 115.3 (1976): 377-393.

9. Schwartz RB., et al. "Diffusion-weighted MR imaging in hypertensive encephalopathy: clues to pathogenesis". American Journal of Neuroradiology 19.5 (1998): 859-862.

10. Morello F., et al. "Hypertensive brain stem encephalopathy: clinically silent massive edema of the pons". Neurological Sciences: Official Journal of the Italian Neurological Society and of the Italian Society of Clinical Neurophysiology 22.4 (2001): 317-320.

11. Mirzamoradi M., et al. "Posterior Reversible Encephalopathy Syndrome (PRES) Associated with Eclampsia: A Case Study". International Journal of Medical Research and Health Sciences 6.3 (2017): 48-53.

12. Faille L della., et al. "Clinical predictors and differential diagnosis of posterior reversible encephalopathy syndrome". Acta Neurologica Belgica 117.2 (2017): 469-475.

13. Hartmann H. "Posterior Reversible Encephalopathy: An Epileptic Syndrome?". Neuropediatrics 48.2 (2017): 064-065.

14. López-García F., et al. "A reversible posterior leukoencephalopathy syndrome”. Review Neurology 38.3 (2004): 261-266.

15. Doelken M., et al. "Differentiation of cytotoxic and vasogenic edema in a patient with reversible posterior leukoencephalopathy syndrome using diffusion-weighted MRI". Diagnostic and Interventional Radiology 13.3 (2007): 125-128. 
16. Ait S., et al. "Cortical blindness and posterior reversible encephalopathy syndrome in an older patient". BMJ Case Report (2012).

17. Fuseau Herrera M., et al. “Diagnosis and management of Posterior Reversible Encephalopathy Syndrome in Systemic Lupus Erythematosus. Case report". Revista Colombiana de Reumatología 26.1 (2019): 74-79.

18. Garg RK. Posterior leukoencephalopathy syndrome". Postgraduate Medical Journal 77.903 (2001): 24-28.

19. Prasad N., et al. "Is reversible posterior leukoencephalopathy with severe hypertension completely reversible in all patients?" Pediatric Nephrology 18.11 (2003): 1161-1166.

20. Roth $\mathrm{C}$ and Ferbert A. "Posterior reversible encephalopathy syndrome: long-term follow-up". Journal of Neurology, Neurosurgery, and Psychiatry 81.7 (2010): 773-777.

\section{Assets from publication with us}

- Prompt Acknowledgement after receiving the article

- Thorough Double blinded peer review

- Rapid Publication

- Issue of Publication Certificate

- High visibility of your Published work

Website: www.actascientific.com/

Submit Article: www.actascientific.com/submission.php Email us: editor@actascientific.com

Contact us: +919182824667 